\title{
Doing Office Work on the Motorway
}

\author{
Eric Laurier
}

\section{Everyday Life on the Motorway}

B

Y COMPARISON with the rivers we have sailed, or the forest paths we have trodden for thousands of years ${ }^{1}$ the motorway is incipient, yet the curious place that is the multi-lane motorway no longer has quite the novelty value it once did. When it first appeared, like the railway before it, the motorway raised a new set of problems: how drivers ought to drive, what kind of vehicles would be allowed, the many things people could not do on such a road and whether it might be worthwhile at all (Merriman, $2001,2004)$. Nowadays we are no longer struck with wonder that it might be possible for hundreds of individual vehicles to travel in close proximity at high speeds without constant fatalities and chaos ensuing. Instead, the motorway has now become one of our ordinary places, a space of convention and an almost unavoidable part of our everyday mobility (Urry, 2004).

In examining driving as a new form of everyday habitability, Nigel Thrift (2004) points out that, while making a hero of the walker in the city street, in terms of transport Michel de Certeau (1984) focused only on the carceral aspects of rail travel. The millions of automobiles already sharing city streets with pedestrians were dealt summarily with as alien invaders. Unwelcome new arrivals, cars were killing cities previously brought to life by creative pedestrian enunciations. While we might have sympathy with de Certeau's lament for the drowning out of the poetry of footfalls on cobbles, 'research on automobility shows the world of driving to be as rich and convoluted as that of walking' (Thrift, 2004). Moreover, in turning our attention to the motorway we find a space where walkers, excepting repair crews, breakdowns and passengers inside coaches, are almost entirely absent. Even though we cannot walk there, we dwell upon the motorway in motion,

- Theory, Culture \& Society 2004 (SAGE, London, Thousand Oaks and New Delhi), Vol. 21(4/5): 261-277

DOI: $10.1177 / 0263276404046070$ 
sometimes alone, sometimes in convoys or side by side in queues and jams. There are plenty of groups, such as commuters, lorry and bus drivers, sales representatives and so on, who spend years of their lives driving along the motorway's parallel lanes. For these mobile communities it has become a landscape charged with daily emotional satisfactions, crises and reflections (Katz, 1999). To take the motorway seriously as one of the distinctive environments of our age we must consider the practices of driving with the care that de Certeau did of walking. In this article I will draw upon approaches to socio-material organization that take seriously the role of recognizable spatial settings such as the pavement, the factory, the public park, the laboratory, the school and the house (Crabtree, 2000; Evergeti, 2003; Hetherington, 1997; Latour and Woolgar, 1979; Lee and Watson, 1993; Ogborn, 1998). These studies have taken particular common places, such as the pavement, as geographically, historically, morally, legally and technologically assembled settings for human dwelling. Here, though, I will approach the motorway through contemporary empirical materials as an important arena for social action, in line with a growing number of analysts (Juhlin, 2001; Katz, 1999; Merriman, 2004; Michael, 1998; Miller, 2001; Murtagh, 2001; O’Hara et al., 2002; Thrift, 2004; Urry, 1999, 2000, 2003; Vesterlind, 2003).

Where de Certeau contemplated the panoptic view of the city and its pedestrians from a skyscraper before shifting down to street level, Bruno Latour has examined what has to be in place to monitor and control motorway systems. In his study of the paradigmatic panopticon of French automobile life - the Paris traffic control centre - Bruno Latour called the view the controllers have of vehicles, an 'oligopticon' (Latour and Hermant, 1998). The complexity and the moral thicket of thousands of individual drivers' actions, reactions, irritations, overtakings, tailgatings, are reduced, transformed and assembled into collective patterns of traffic flows (similarly see the work on traffic engineers in Garfinkel, 2002). Clearly it is not only for traffic controllers that vehicles in motion are reduced to restricted and relevant 'observables' (Sacks, 1972); ${ }^{2}$ the same is true of what drivers can see. In what follows I want to drop back down to 'motorway level', as Katz (1999) and Michael (1998) have done, to consider the driver's perspective, and indeed also take up the passenger's perspective in the car interior. This is a relatively under-utilized point of view which offers the possibility of descriptions of 'the comportment of the driver within the car' (1998: 126) as it is bound up with the passenger's awareness, as an occupant of the same vehicle, of what is happening to the driver as a member of the 'society of traffic' (Lynch, 1993) responsive to other drivers' actions.

For the driver analysing the traffic in which they are travelling, they and other drivers can only produce and recognize a limited repertoire of observables, compared to the richness of face-to-face encounters (Goffman, 1956; Katz, 1999). Driving at night on unlit roads guided by the light signals of other vehicles is, as Lynch (1993) notes, accomplished with an amazingly minimal environment of visible gestures. Yet despite the pared-down visible 
features of traffic on motorways, Eric Livingston succinctly argues, drivers, sometimes with ease and sometimes with effort, collectively and locally produce the witnessable details that are required for the continuing orderliness of traffic.

Drivers, as members of a production cohort - and as members of a production cohort, as analysts of its and their own order-productive work - produce and maintain the witnessable details of their local driving circumstances. The ways that they do so are identical with the ways that they make their driving 'account-able' - they are witnessably changing lanes, slowing down, trying to get to the off-ramp. Therein, they produce together the relatively stable features of freeway traffic flow. These consist, in fact, of their relatively stable, locally produced and regulated driving practices. (Livingston, 1987: 84)

Each member of the production cohort of motorway traffic is a 'polyvalent' person who has membership of, responsibilities for and commitments to other societies that are inescapably brought on to the motorway. 'Doing being a driver' as Sacks (1984) might say, on the motorway is never enough to fully occupy the locus of accountable activity that is an intelligible and reflective actor (Laurier and Philo, 1999; McHugh et al., 1974). And 'doing being a passenger' is less demanding still. Seldom do any of us just 'go for a drive' on the motorway; ${ }^{3}$ it is busy, as I will develop later, with all kinds of other work.

\section{Mobile Workplaces}

Driving on the motorway, as an almost inescapable part of their jobs, carbased service sector employees sit for too long, get stuck in traffic jams, make mobile phone calls when they should not and break the legal speed limit to arrive at meetings on time. Some of these car-based workers can do their correspondence, figures and form-filling admin either while parked up in car parks or at their homes; however, the majority do not have this luxury. Long journey times, which are common in large company regions, or delays in slow-moving traffic mean that days on the road tend to be driving mostly and very little 'work', that is, if driving was really the only thing that business persons did on motorways. In fact it was the norm among the carbased employees, in the research project out of which this article arises (Laurier and Philo, 1998), that they and their co-workers worked, while driving, to get their jobs done. These risks of the job were not recorded by the technologies of surveillance used by their companies (in contrast to the way that, say, HGV driving is monitored) and hence were not rendered accountable to their institution. For the mobile workers we studied, there was a surprising lack of deliberate planning by companies who did not yet treat the growing daily mobility of their personnel with the same precision as the long-standing logistics of their products. Little recognition has been given to the fact that, when changes in technology and commercial company policy move staff out of their traditional office and on to the roads in their regions, then not all the work can be divided so that one person in one car 
can do it appropriately, safely and in coordination with their non-proxemic co-workers, given that they are also responsible for transporting themselves (Esbjornsson and Juhlin, 2002; Juhlin and Vesterlind, 2002).

By way of comparison, ambulances, fire engines, bin lorries, police cars, ships and passenger aircraft have 'staff' who work in pairs or larger groups, so that tasks can be distributed and also so that, for each 'driver', there is someone to whom their conduct is witnessable and immediately and retrospectively accountable (Hutchins, 1995; Ikeya, 2003; Kawatoko and Ueno, 2003; Watson, 1999). In these latter cases there is too much work for one person in moving these vehicles around while accomplishing the organizational tasks they are required to do (i.e. delivering and preparing patients for hospital; collecting, sorting and rejecting rubbish bags; flying and servicing air passengers). There are examples of one-person one-vehicle working arrangements such as taxi- and lorry-driving, though in each of these cases the job is in itself the transportation of persons or goods (Agar, 1986; Davis, 1950; Hollowell, 1968; Psathas and Henslin, 1967; Verrips and Meyer, 2001), whereas the jobs that are now moving into the car are regional management, personnel, sales support, credit control and so on. In an important sense, driving and its contingencies are potentially problematic since they necessarily take priority with the person-as-driver in terms of avoiding crashes and collisions, while for the person-as-office worker these pressing concerns are not straightforwardly available to the awareness of remote co-workers and clients. At the same time, the other jobs that are done during motorway journeys, and the purposes of journeys themselves, be they trivial, routine or highly important, are obscure matters to other drivers. As Katz (1999: 35) puts it: 'each driver usually will have no way of appreciating where other drivers are going and why, unless traffic stops completely and drivers exit their cars to converse with each other'. And for Katz's stressed LA drivers this lack of mutual awareness, beyond the mutual organization of traffic, is the source of many of their emotional outbursts. Drivers can show they are in a hurry, although unless they are ambulance drivers or couriers they cannot quickly display why they are in a hurry.

For other drivers, then, there is only limited awareness that, even as the business people are speeding along motorways, they are likely to be busy doing desk-work: trying to keep up with complaints from clients, requests for help from colleagues and dictating letters to secretaries; trying to keep to optimistic appointment times with clients and colleagues; trying to stay in synch with those who do not have to drive to meetings; trying to do office work with paper documents; and on their mobile phone to recoup time otherwise lost in transit (Brown et al., 2002; O'Hara et al., 2002). These varieties of desk work and the dashboard equipment of driving have not been designed to go together, yet the office workers we studied managed to artfully combine them. They have done so because they have to, yet they do not do so blindly, without skill or without feeling morally accountable for their actions. To be reasonable, to drive with care, a driver has to detect the occasions and conditions on the road where other tasks can be initiated with 
minimum risk (Laurier, 2002). The motorway, as I will go on to detail below, is a simplified road system with no contraflow, multiple lanes for manoeuvre, speed matching and easy overtaking. Slow-moving traffic, lights and minor jams also provide occasions where, for practical purposes, the demands of driving slow down, are regularly paced or stop altogether, although even these moments, captured on the wing, are not ideal, since traffic flow can resume before a document is done with or a phone call is finished. Given their unpredictable duration they require the active coordination of the temporal disjuncture between the activity of driving and their workplace tasks; time has to be made by the driver-talker. This gives us a formulation of the car worker's problem as being involved in the joint production of two sequentially organized activities or production cohorts: traffic and office work. ${ }^{4}$

Drawing on a single instance, originally filmed on video and reviewed for the purposes of this article, I want to pursue in more detail how driving, talking and office work are woven together as a practical real-time matter. Or, perhaps more appropriately, how they are sometimes done seemingly beside one another or subsequent upon one another, consequent upon one another or cannot be combined at all (Laurier, 2002). Finding how this is done, because it is done, can only be discovered in the details of actual unfolding singular events. The episode from life on the motorway that I want to examine is from the ethnographic fieldwork of car as workplace project mentioned earlier (Laurier and Philo, 1998), wherein observations of and reports from drivers were collected during fortnights spent shadowing them and travelling as an observer-passenger in their cars (for a similar mobile methodology see Katz, 1999).

\section{Naturally Organized Multi-tasking on the Motorway}

Here it is necessary to point out that readiness to answer questions about one's actions and reactions does not exhaust the heed we pay to them. Driving a car with care reduces the risk of accidents as well as enabling the driver to satisfy interrogations about their operations. Applying our minds to things does not qualify us only to give veracious reports about them, and absence of mind is betrayed by other things than merely being non-plussed in the witness box. The concept of heed is not, save per accidens, a cognitive concept. Investigations are not the only occupations in which we apply our minds. (Ryle, 1949: 132)

'Ally', one of the participants in our project, was employed by a car leasing company, and spent three out of five days a week on the road, visiting clients around the M4 corridor (a stretch of motorway connecting London and Bristol). The episode I would like to consider occurred on a three-lane motorway. That we are looking at a stretch of motorway, rather than an urban clearway or suburban cul-de-sac, is a key starting point since, for competent drivers, to adapt an expression of Rod Watson's, 'the physical configurations comprising' a motorway are 'clearly, perceptual categories of an 
especially salient kind', and that they present 'loci for a whole range of special driving techniques that [are] locally deployed in that highly particular situation' (1999: 52). This singular character of the motorway is recognized in driving instruction, as learners are prevented from driving there until they have acquired greater competency in the basic techniques of driving. Equally a three-lane motorway carries with it expectations, legally enforced obligations and 'aligned intermediaries', so that, like the French TGV high-speed train of Latour's example, 'nothing interrupts [the vehicle] or slows it down' (1997); there should be no unpredictable or slow-moving learners, nor parked cars, pedestrians crossing, children playing football, cyclists, dogs, cross traffic or oncoming traffic. Alongside its exclusions of all but competently driven fast vehicles, the motorway is built to provide a visually supportive environment for speed under normal conditions; you can see things coming from a long distance away (Venturi et al., 1988). It has no hairpin bends, no hidden entrances and it has wide lanes, cambered corners and gentle inclines. It has a fast lane, a middle lane, a slow lane and a hard shoulder. You cannot park. You cannot picnic (Merriman, forthcoming). Although this is not strictly relevant to what follows, it is statistically the least likely place to have a car accident.

Not only do roads, by being 'motorways', 'dual carriageways', 'country roads', 'dirt tracks in forests' (Watson, 1999), provide categorially organized expectations of hazards, acceptable speeds, absence or presence of oncoming traffic and so on, but they also have typical rhythms that their regular drivers get to know (similarly for the London underground see Heath et al., 1999): they are busy and quiet at certain times of day, different kinds of traffic dominate different sections and also vary according to the time of day (parents collecting children from school, delivery vehicles parking up, bin collection, inter-city commuters). On assembling the type of road by its time of day, its normal busyness or quietness and other local features, in the course of driving, mobile workers such as Ally then make assessments as to whether they might be able to get their paperwork out, make a few quick phone calls or make long phone calls, or whether they have to stick to driving alone.

Ally is travelling fairly rapidly along the motorway and is working her way through a number of printed-off e-mails, flicking through them as they are balanced on her lap and mine (see Still 1). In syncopation with extendedly scanning the road ahead, she glances across and down at the in-tray of printed e-mails balanced on my lap. If she did not have an ethnographer in the car beside her today, the documents would be balanced on the passenger seat. With my assistance in sorting through a large pile, she selects two documents and places them on the steering wheel in front of her before making her phone call. Once the document is on the steering wheel Ally talks quietly through the documents saying who she has to phone next, what will be difficult in the phone call.

After reading the e-mails through she leaves them in her grip on the steering 


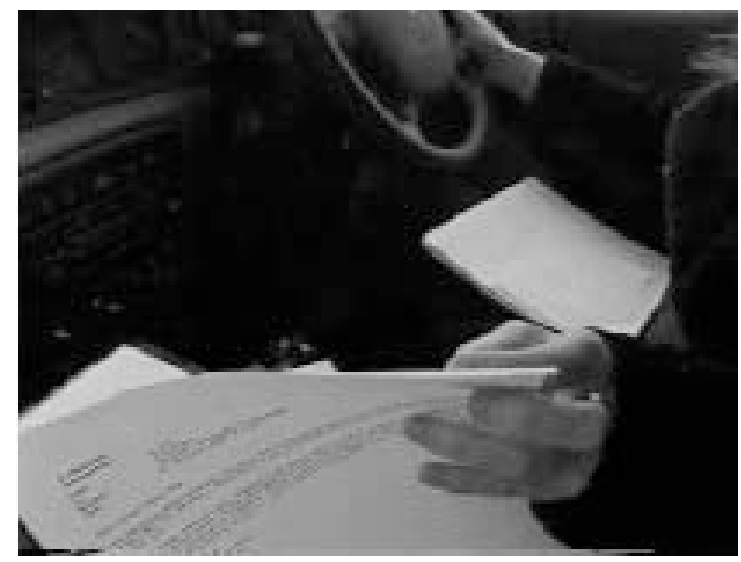

Still 1 Ally driving and doing paperwork

wheel so that she has them available should she need to consult them while she makes her phone-call (see Still 2). After a while our vehicle begins closing in on a slower-moving vehicle in our lane. Ally mutters 'Get out the way', slightly louder than her talking through the documents. On seeing a gap in the fast lane, Ally indicates and pulls out, looks at the rear view mirror and, over her shoulder, waves thanks to a driver who has let her pull out. As she speaks, she makes a forward indicating gesture toward the road with her free left hand and says 'I must concentrate on my driving for just a little while.' I laugh in response.

In the above vignette, rendered from a video recording, we encounter a switch between doing work on the motorway and doing driving on the motorway as activities to which we (driver, passengers and, perhaps, video

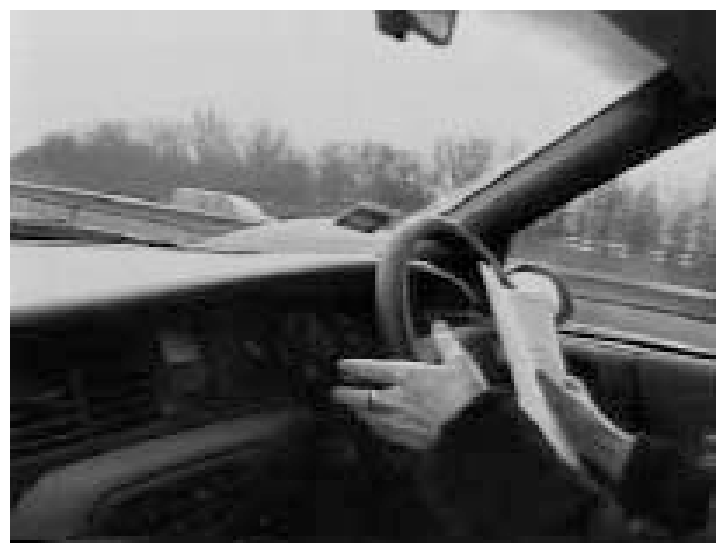

Still 2 Ally holding document on wheel whilst flicking indicator 
viewers) should pay heed. In line with Watson's (1999) remarks on the omnirelevance within the vehicles of the categories driver and passenger for Ally and myself, 'Get out the way' was hearable by me, as passenger, as a switch from her earlier buzzing over her paperwork. It is hearable by a passenger as a potential initiation into a conversational sequence ('announcement' 'response' [Watson, 1999]), as were the many other commands, compliments and insults directed at other drivers and collected by ourselves during our project and by Katz (1999). This produces a passenger's analysis of the announcement as one that does nothing to the other drivers. If such a remark is not directed at other drivers, nor is it a quiet mutter about paperwork, then what does it do to me (or any other person) as a passenger? It perhaps calls upon one as a passenger to find in the scene ahead what the driver has formulated (Goodwin, 1997) and offers one, as passenger, a space for response as to whether they are willing to join the other, as driver, in their analysis and moral assessment of the traffic object that has elicited their remarks (e.g. in this case as an obstacle in the way). ${ }^{5}$ Ought they to add an agreeing 'Move over slow coach', or defend the other driver or offer alternative mundanely reasonable versions of what has happened and what is currently happening on the road (Pollner, 1987)?

While much is made of the inability of drivers to speak to one another in contrast to pedestrians, and how that leads to the build up of misunderstandings that can explode into moments of road rage, less is made of the freedom to say aloud what pedestrians usually keep quiet. 'Get out the way' is an unhearable and thus unfollowable instruction toward the slow-moving vehicle ahead. To go further, it stands as a remark that should not be heard, a form of words out of the other driver's earshot. Its utterer would not in fact want to be caught by the other driver saying such a thing. In this sense none of the compliments, announcements, remarks or worse that drivers say about other drivers in the overhearing-proof space of the motorway are truly commands, compliments and insults since they cannot be received. Katz (1999) picks out numerous actions that do count as gestures discernible by other drivers, horns are an obvious possibility, and Katz brings out the artful ways in which 'flipping off' (i.e. giving the finger) is done and the uses of tailgating to attempt to force other drivers to yield to a car behind. Equally, he draws on the affective response that tailgating elicits from the driver to whom it is being done.

'I must concentrate on my driving for a while' - Ally makes a comment on what she, as an incumbent of the category 'driver', ought to be doing. In response I laugh. This seems curious. What could be going on here? Her comment comes after her free hand's gesture: uncurling and sweeping toward the view of the motorway ahead. A gesture that builds on the announcement and the ongoing course of action directing the passenger's gaze toward the view out of the front window as the scene to which heed should be paid. Beyond trading on the omnirelevance of driver/passenger relations, another way that Ally has made this remark a comment at which one could laugh at the time is by its placement in relation to the preceding 


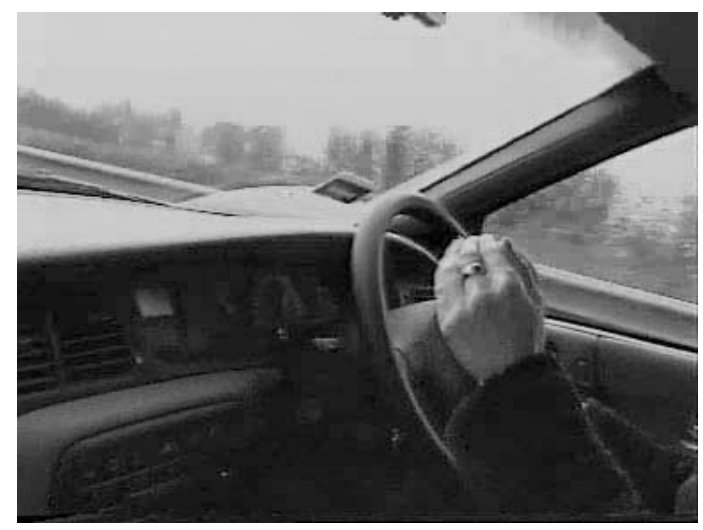

Still 3 Start of hand sweep: 'I must concentrate on my driving for a while'

long stretch of our collaborative sorting through of e-mails, where she can be taken to have been failing to be attentive to driving. Nevertheless, what she had in fact done immediately preceding her ironic and reflexive comment on her driving, was to notice an obstacle in 'the way' ahead and to stop sorting through her e-mails. It is in her comment's sequential organization, coming after a specific driving action: overtaking, that we see it as a formulation of her driving. During this admittedly brief action (about 5 seconds) she did indeed devote her entire attention to driving, stopping talking to herself and to me. With an extended glance (Sudnow, 1972) in her rear-view mirror she checked on the intentions of the driver in the fast lane who, seeing her indicating that she wanted to overtake, let her out by slowing down slightly, making, and thereby offering, a gap for her. The switch between the paperwork and devoting full attention to driving was obvious from within the car in terms not just of the work Ally's hands were doing but also the long look directed at the mirror and the road ahead. Once in the fast lane Ally waved thanks to the fast-lane driver by raising her hand to window height in a temporally extended gesture making an observable gesture of gratitude oriented to the rhythm of glances being used by the driver behind ${ }^{6}$ (see Katz, 1999 on the timing of gestures). Ally's gratitude recognizes a generous act on the motorway, an act and response that reminds us that driving is not all a Goffmanesque manoeuvring among strangers (Raffel, 2001).

\section{Fast Subjects Cruising}

During the time when Ally stops reading her e-mails, as part of the social organization of the motorway, she is doing an accountable action - [overtaking $]^{7}$ - in contrast to which the rest of her driving could be said to be merely [cruising] along the middle lane. ${ }^{8}$ Overtaking is known by competent drivers as a period of increased risk for all involved and it is an achievement in that attempts can succeed or fail. It is, relatedly, a highly moralized 
and often emotive action on the motorway, since success and failure are involved, which requires additional care (Jayyusi, 1984; Katz, 1999). In a contra-flow system the car is being put into the face of oncoming traffic; on a motorway a gap has to be found in the fast(er) lane. If overtaking is done without care by either the overtaker or the overtaken or the gap-offerer it produces a 'cut-off' for one or the other driver (and for the righteous rage that follows see Katz, 1999). The speed of the car in relation to the vehicles ahead and in parallel lanes requires monitoring and adjusting. Alongside this the path of the vehicle needs to be altered to get in and out of the gap in the fast lane. [Overtaking] like dialogue in talk has its opening sequences between the parties, through the indicator as a request, the gap as an offering, the pull out, the slow motion moment of passing the other vehicle, pulling back in and potentially thanking the gap-offerer. It is hopefully becoming apparent in describing a short actual episode of driving like this in detail that driving can be decomposed into multiple accountable, locally identifiable and morally charged actions (e.g. overtaking, cruising, slowing down, exiting, speeding, cut-offs, blind-siding) which require their reflexive use in relation to time-bound spaces to maintain the endogenous production of motorway traffic. In the initiation of moral (and legal) inquiries as to whether someone was driving without due care and attention it is the particulars of the situated actions that are analysed and morally assessed on the motorway rather than driving in general (Jayyusi, 1984; Pollner, 1987). In accomplishing her multi-tasking without accident Ally is thus analysing the emerging details of the motorway traffic (the sweep of her hand toward the road ahead) to find spaces in which to do her office work.

The motorway is a form of road supportive of cruising in a manner that city centre streets, suburban cul-de-sacs and un-metalled forest roads are not. While the motorway is a place that regularly produces conditions for cruising, cruising, since it is easy driving, does not fully occupy competent drivers such as Ally. She would not be a competent driver if she could not do [cruising] with this relative ease. After all, would it not be peculiar to cruise the motorway attentively unless this meant that you were driving this way in order to gaze at the scenery and sites (which means again that you are attending to the landscape as well)? The driver is always a driver in traffic and thus cannot rely on the motorway as a place in which to sit as some individualized consciousness perceiving a static environment; drivers are part of traffic which produces them and, at the same time, they have to analyse the traffic to find it to be normal free-flowing, and to see such a thing not as a momentary event but as a recognizable territory, large enough to provide the occasion for cruising at high speeds. Once drivers have established that they are in a setting in which they can cruise, and they do then cruise, they can justifiably let their concentration shift to other things. For some drivers this may be daydreaming, for the car-based company employee, it will almost always be their work. In summary though, if a driver can find a space in the traffic for cruising then he or she has also found a 
safe space for work, and his or her assessment of risk is not simply correlated with the speed of a vehicle.

What is perhaps less obvious is that cruising has a steady and stable speed which the driver produces and maintains in relation to the traffic flow and the kind of road they are on. ${ }^{9}$ When Ally finds herself approaching another vehicle also cruising in the middle lane (the emerging problem which occasions her overtaking) then this happens because her cruising is set by herself at a particular speed. She could slow down to the pace of the vehicle in front, yet there is a preference to avoid doing so on the motorway, a preference to maintain the particular speed that is your speed. For Ally, an avowedly 'fast driver' 10 this was around $85 \mathrm{mph}$ (while on the motorway she checked her speedometer intermittently to see if she was far above or below it). As Ryave and Schenkein (1974) note with respect to walking, by slowing down your movement and falling into step behind a pedestrian in front, the appearance is produced of 'following' the other. On the motorway if one stays in lane and slows down on approaching another vehicle, then, if the situation continues, it can be seen as sitting on the tail of the other or, worse, of tailgating. ${ }^{11}$ Given that Ally selects a speed appropriate to traffic flow and road type, and given, second, that Ally is a fast driver, she ought never to approach other drivers like her. If she is driving as a driver of her kind, the regular drivers that she catches up on are 'slow' drivers. If appropriate speeds are judged in relation to category of road as setting, categorization of one's driving style (e.g. fast, careful, average, in a hurry) then speed, as Latour remarks of space and time, is:

... not the Newtonian sensoria in which events and planets fall along ellipses. But they are not, either, the forms of our perception, the universal a prioris that our mind has to use in order to frame or accommodate the multiplicity of beings and entities. Far from being primitive terms, they are, on the contrary consequences of the ways in which bodies relate to one another. (Latour, 1997: 176)

If we accept that drivers, in using a motorway for cruising along its lanes have a speed that is theirs, and at others times use 'slow' or 'fast' as relational assessments of the way their car relates to other cars, then we can begin to critique the theorists who constantly write of the desire for speed as if it were simply going as fast as anyone possibly can (Michael, 1998; Sachs, 1984; Virilio, 1987). Harvey Sacks shows that traffic is tremendously adaptable to events such as accidents and road repairs and that fast and slow drivers adapt in turn to the traffic in which they find themselves. As he puts it in describing how 'fast / with traffic / slow' are used in and endogenous to traffic across whatever and wherever driving conditions are found without reference to the speedometer:

... what would other theorists do with it [traffic]? Would they find it tremendously puzzling, i.e. everybody ought to be driving fast, if fast is something 
that permits, expressions of, say, strength or whatever else? (Sacks, 1992: 440)

Sacks goes on to point out that, when drivers find themselves on empty roads in an unfamiliar country without traffic to judge by, they suffer from a lack of a sense of what constitutes fast or slow or average on these roads, and in those sorts of situations may be forced to turn to the speedometer and road signage. The rest of the time drivers, if they are fast drivers, can rely on the traffic around them to produce a relative speed that is faster than the average speed of that traffic. They are always catching up with the car ahead, they are unhappy sitting in the middle of a chain of cars travelling at the average speed, and they are always trying to overtake. They show themselves to be fast drivers by doing so and they are seen to be fast drivers by doing so.

\section{Moralizing the Fast and the Slow}

Throughout the article I have refrained from assessments of the morality of driving and working on the motorway, which in its refusal is, in a way, an appraisal in itself. Rather than try and work up a superior or more nuanced moral standpoint on the wrongness or rightness of Ally and other car-based workers doing office work while driving though, I would like to conclude by turning, albeit briefly, to how the moralizing of speed is accomplished. Drawing on ethnomethodological approaches, particularly Harvey Sacks, Jayyusi (1984) provides an extended examination of morality in action. She emphasizes how potential moral inferences based on 'speed', setting, character, risk are open to transformation as part of ordinary contests, disagreements and justifications. She uses Hell's Angels as a conspicuous example of divergent moral orders, wherein what they do will be analysed by reference to membership of their order by outside and by themselves. On the motorway, among the non-deviant, slow drivers can class themselves as 'careful drivers', fast drivers categorize slow drivers as 'Sunday drivers', 'caravans' or 'idiots' (if for instance they are sitting in the fast lane). In Sacks's (1992) example, being a fast driver is transformed and used for building membership of the rebellious class of kids that were hot-rodders in the US in the 1960s. Fast driving is open to further transformation since it is given an immoral ascription also which builds hot-rodders up as the kind of troublesome youths who are on the receiving end of the moral judgements of conventional society and end up attending therapy sessions or being sent to jail. Ally, although an avowedly fast driver, does not belong to the 'morally organized communities' of the Hell's Angels or teenage hotrodders, so she cannot use such membership to transform her fast driving according to the conventions of those communities. Fortunately, she is a member of those car-based mobile service workers who, at the time of the research project, were frequently being called 'road warriors'. Just as a business class traveller expects to speed through airport check-ins, conduits and departures, Ally claimed a certain entitlement to travel faster than ordinary motorway users. For her it is her regular workplace and she has 'things to do, places to go'. 
Given that traffic and the arrangement of the motorway into lanes provide for the coexistence of fast, average and slow drivers, and relatedly that such measures of speeds are used, sometimes disjunctively, in the moral and legal attribution of care or carelessness in driving, how does speed articulate with Ally's office work? We can begin to visualize how fast drivers become angry about the speed and lane selection of other drivers (e.g. Ally's 'Get out the way') but also how having a speed and keeping to it may conflict with the extra care that doing office work at the same time may require. Being a fast driver and an office worker is a morally precarious position to attempt to achieve, especially since, as we noted at the outset, driving slowly is the exception to the norm and, unless carefully defended, may lead to career- and character-troubling attributions of slowness in the fast-moving world of business. To make the instructive comparison once more, the business traveller at the airport is the fast traveller, with curtailed checkin times, short-cuts through the airport, hand luggage only and so on. In closing then, we can speculate on whether we could have a world where business travellers were the slow travellers among us and not just on the motorway.

Notes

1. One distinction of the 'road' is that we no longer share it with other animals, unlike rivers and paths. The road (like the railway) is a departure point for a sociotechnical development whose current azimuth is the motorway. On the motorway nothing travels under its own locomotion apart from vehicles with combustion engines; even the horse-drawn carriage is banned (though horses, dogs, sheep, cattle and so on can travel inside vehicles as docile passengers or mere cargo).

2. Notoriously, for the purposes of police surveillance and speeding fines it is the number plates and makes of cars that can be photographed by CCTV and 'gatso' speed cameras. However, these cameras are not everywhere, nor are all of them loaded with film and well-travelled drivers get to know these geographies of road surveillance (Heath et al., 1999), so the police are not watching drivers 'unaware' as it were. What we will be concerned with here is not how a driver might go about showing what they are up to on the roads to the police or other authorities on the road, or hiding it from them.

3. This is not to deny that there may be occasions when driving is undertaken for pleasure, though this may well be bound up with looking at landscapes (Crang, 1997; Rojek and Urry, 1997) or listening to music or conversing with friends.

4. There are work situations on the telephone when there is a similar problem, for example in telebanking where the activities of typing at the keyboard, waiting for the computer to respond and then reading off the screen are implicated in the organization of the conversation (Hughes et al., 1999; Tolmie et al., 1998).

5. An excellent study of how a problem comes to be realized in a visual scene can be found in Goodwin (1997).

6. On similar timing issues of gestures in successfully and artfully 'flipping off' another driver see Katz (1999). Part of the satisfaction is catching the other driver registering the insult, since drivers get to know when insults are coming through the positioning of vehicles (pulling alongside or in front) and can make sure they are looking elsewhere. 
7. Square brackets are a notation device to indicate a phenomenological or ethnomethodological suspension of a term's meaning in order to examine what constitutes such a thing.

8. It is under such conditions that, in luxury cars, 'cruise control' can be switched on since driving does not place exacting demands on the driver - it is relatively automatic, requiring that the car be kept in lane and at a safe distance from vehicles ahead.

9. A concise description of the production of freeway traffic through drivers' local driving practices can be found in Chapter 7 of Livingston (1987).

10. Ally had selected a sporty car model to drive and in this way 'dressed' herself to display herself as a fast driver. Another of our research participants, Penny, was an avowedly careful driver. She maintained a steady $65 \mathrm{mph}$, drove a sizeable saloon model and was, as often as not, in the slow lane.

11. In busy single-lane city roads, and of course in traffic jams, at junctions, exit ramps and so on, queues of vehicles are common and quite acceptable. They are not seen as purposefully constructed by drivers behind and can thus be utilized by drivers without being seen as tailgating.

\section{References}

Agar, M.H. (1986) Independents Declared. The Dilemmas of Independent Trucking. Washington, DC: Smithsonian Institution Press.

Brown, B.A.T., N. Green and R. Harper (eds) (2002) Wireless World: Social and Interactional Aspects of the Mobile Age. London: Springer.

Crabtree, A. (2000) 'Remarks on the Social Organisation of Space and Place', Journal of Mundane Behaviour 1: http://www.mundanebehaviour.org/issues/vlnl/ crabtree.html.

Crang, M. (1997) Cultural Geography. London: Routledge.

Davis, F. (1950) 'The Cabdriver and His Fare: Facets of a Fleeting Relationship', American Journal of Sociology 45: 158-65.

De Certeau, M. (1984) The Practice of Everyday Life. London: University of California Press.

Esbjornsson, M. and O. Juhlin (2002) Placememo - Supporting Mobile Articulation in a Vast Working Area through Position-based Information. Stockholm: Interactive Institute, Mobility Studio.

Evergeti, V. (2003) 'Paper Mail and the Social Organisation of Space', pp. 70-86 in T. Lask (ed.) Constructions sociales de l'espace: les territoires de l'anthropologie de la communication. Liège: Les Éditions de l'Université de Liège.

Garfinkel, H. (2002) Ethnomethodology's Program, Working Out Durkheim's Aphorism. New York: Rowman and Littlefield.

Goffman, E. (1956) The Presentation of Self in Everyday Life. Edinburgh: Edinburgh University Press.

Goodwin, C. (1997) 'Transparent Vision', pp. 370-404 in E. Ochs, E.A. Schegloff and S.A. Thompson (ed.) Interaction and Grammar. Cambridge: Cambridge University Press.

Heath, C., J. Hindmarsh and P. Luff (1999) 'Interaction in Isolation: The Dislocated World of the London Underground Train Driver', Sociology 33: 555-75. 
Hetherington, K. (1997) The Badlands of Modernity. London: Routledge.

Hollowell, P.G. (1968) The Lorry Driver. London: Routledge and Kegan Paul.

Hughes, J., J. O’Brien, D. Randall, M. Rouncefield and P. Tolmie (1999) 'Virtual Organisations and the Customer: How "Virtual Organisations" Deal with "Real" Customers', Lancaster University, available online: http://www.comp.lancs.ac.uk/ sociology/VSOC/YorkPaper.html.

Hutchins, E. (1995) Cognition in the Wild. London: MIT Press.

Ikeya, N. (2003) 'Practical Management of Mobility: The Case of the Emergency Medical System', Environment and Planning: A 35(9): 1547-64.

Jayyusi, L. (1984) Categorization and the Moral Order. London: Routledge and Kegan Paul.

Juhlin, O. (2001) 'Traffic Behaviour as Social Interaction - Implications for the Design of Artificial Drivers', pp. 19-38 in H. Glimell and O. Juhlin (eds) The Social Production of Technology: On the Everyday Life of Things. Goteburg, Sweden: BAS. Juhlin, O. and D.N. Vesterlind (2002) 'Bus Driver Talk - Current Practice and Future Communication Support', available online at http://www.sts.gu.se/roadtalk. html.

Katz, J. (1999) How Emotions Work. London: University of Chicago Press.

Kawatoko, Y. and N. Ueno (2003) 'Technologies Making Space Visible', Environment and Planning A 35(9): 1529-45.

Latour, B. (1997) 'Trains of Thought: Piaget, Formalism and the Fifth Dimension', Common Knowledge 6: 170-91.

Latour, B. and E. Hermant (1998) Paris, ville invisible. Paris: La Découverte.

Latour, B. and S. Woolgar (1979) Laboratory Life: The Social Construction of Scientific Facts. London: Sage.

Laurier, E. (2002) 'Notes on Dividing the Attention of a Driver', Team Ethno Online http://www.teamethno-online.org/.

Laurier, E. and C. Philo (1998) Meet You At Junction 17: A Socio-technical and Spatial Study of the Mobile Office, ESRC report. Glasgow and Swindon: Dept of Geography, University of Glasgow and ESRC.

Laurier, E. and C. Philo (1999) 'X-morphising: A Review Essay of Bruno Latour's Aramis or the Love of Technology', Environment and Planning A 31: 1043-71.

Lee, J.D.R. and D.R. Watson (eds) (1993) Interaction in Urban Public Space, Final Report - Plan Urbain. Manchester: Dept of Sociology.

Livingston, E. (1987) Making Sense of Ethnomethodology. London: Routledge and Kegan Paul.

Lynch, M. (1993) Scientific Practice and Ordinary Action: Ethnomethodology and Social Studies of Science. Cambridge: Cambridge University Press.

McHugh, P., S. Raffel, D.C. Foss and A.F. Blum (1974) On the Beginning of Social Inquiry. London: Routledge and Kegan Paul.

Merriman, P. (2001) 'Cultural Geographies of Road Building and Protest in England since 1950', PhD thesis, University of Nottingham.

Merriman, P. (2004) 'Driving Places: Marc Augé, Non-places, and the Geographies of England's M1 Motorway', Theory, Culture \& Society 21(4/5): 145-67.

Merriman, P. (forthcoming) " Mirror, Signal, Manoeuvre”: Assembling and 
Governing the Motorway Driver in Late Fifties Britain', in S. Böhm, C. Jones, C. Land and M. Paterson (eds) Rethinking Automobility: Representation, Subjectivity, Politics.

Michael, M. (1998) 'Co(a)gency and the Car: Attributing Agency in the Case of the "Road Rage", pp. 125-41 in B. Brenna, J. Law and I. Moser (eds) Machines, Agency and Desire. Oslo: TVM.

Miller, D. (ed.) (2001) Car Cultures. Oxford: Berg.

Murtagh, G. (2001) Location-based Services : A Study of In-car Navigation Systems. Guildford: Digital World Research Centre, University of Surrey.

Ogborn, M. (1998) Spaces of Modernity: London's Geographies 1680-1780. New York: Guilford Press.

O'Hara, K., M. Perry, A. Sellen and B. Brown (2002) 'Exploring the Relationship between Mobile Phone and Document Activity During Business Travel', pp. 180-94 in B. Brown, N. Green and R. Harper (eds) Wireless World: Social and Interactional Aspects of the Mobile Age. London: Springer.

Pollner, M. (1987) Mundane Reason. Cambridge: Cambridge University Press.

Psathas, G. and J.M. Henslin (1967) 'Dispatched Orders and the Cab Driver: A Study of Locating Activities', Social Problems 14: 424-43.

Raffel, S. (2001) 'On Generosity', History of the Human Sciences 14: 111-28.

Rojek, C. and J. Urry (eds) (1997) Touring Cultures, Transformations of Travel and Theory. London: Routledge.

Ryave, A.L. and J.N. Schenkein (1974) 'Notes on the Art of Walking', pp. 265-74 in R. Turner (ed.) Ethnomethodology. Harmondsworth: Penguin.

Ryle, G. (1949) The Concept of Mind. London: Hutchinson.

Sachs, W. (1984) For Love of the Automobile. Berkeley: University of California Press.

Sacks, H. (1972) 'Notes on Police Assessment of Moral Character', pp. 280-93 in D. Sudnow (ed.) Studies in Social Interaction. New York: Free Press.

Sacks, H. (1984) ‘On Doing Being Ordinary', pp. 413-29 in J.M. Atkinson and J.C. Heritage (ed.) Structures of Social Action. Cambridge: Cambridge University Press.

Sacks, H. (1992) Lectures on Conversation, vol. 1. Oxford: Blackwell.

Sudnow, D. (1972) 'Temporal Parameters of Interpersonal Observation', pp. 259-79 in D. Sudnow (ed.) Studies in Social Interaction. New York: Free Press.

Thrift, N. (2004) 'Driving in the City', Theory, Culture \& Society 21(4/5): 41-59.

Tolmie, P., J. Hughes, M. Rouncefield and W. Sharrock (1998) 'Managing Relationships - Where the "Virtual" meets the "Real", Conference paper given at EASST, Edinburgh (copies available from the authors).

Urry, J. (1999) 'Automotility, Car Culture and Weightless Travel', Department of Sociology, Lancaster University, available online at: http://www.comp.lancaster. ac.uk/sociology/soc008ju.html.

Urry, J. (2000) Sociology beyond Societies: Mobilities for the Twenty-first Century. London: Routledge.

Urry, J. (2003) 'Social Networks, Travel and Talk', British Journal of Sociology 54: 155-75.

Urry, J. (2004) 'The "System" of Automobility', Theory, Culture \& Society 21(4/5): $25-39$. 
Venturi, R., D.S. Brown and S. Izenour (1988) Learning from Las Vegas, revised edn. London: MIT Press.

Verrips, J. and B. Meyer (2001) 'Kwaku's Car: The Struggles and Stories of a Ghanian Long-distance Taxi-driver', pp. 153-84 in D. Miller (ed.) Car Cultures. Oxford: Berg.

Vesterlind, D.N. (2003) 'Where Do I Use My Electronic Services? Ambiguity and Interaction at the Petrol Station', Working Paper. Stockholm: Interactive Institute (copies available from the author).

Virilio, P. (1987) 'Negative Horizons', trans. Mark A. Polizzoti, Semiotext(e) 13: 163-80.

Watson, R. (1999) 'Driving in Forests and Mountains: A Pure and Applied Ethnography', Ethnographic Studies 3: 50-60.

Eric Laurier is a Research Fellow at the Department of Geography and Geomantics, University of Glasgow. He has carried out research on social interaction, working in cars, technology and urban life, community in suburbia, human-animal relations and wayfinding with maps. His current research project is an ESRC-funded study of cafes and civil life in contemporary cities. 